\title{
Risk factors for still birth: a hospital based case control study
}

\section{Sujatha Thankappan Lakshmi ${ }^{1}$, Uma Thankam ${ }^{1 *}$, Preetha Jagadhamma ${ }^{1}$, Anuja Ushakumari ${ }^{2}$, Nirmala Chellamma', Sankar Vaikam Hariharan'}

\footnotetext{
${ }^{1}$ Department of Obstetrics and Gynecology, ${ }^{2}$ Department of Community Medicine, Sree Avittom Thirunal Hospital, Government Medical College, Trivandrum, Chennai, India
}

Received: 23 December 2016

Accepted: 31 January 2017

\author{
*Correspondence: \\ Dr. Uma Thankam, \\ E-mail: uma.thankam@gmail.com
}

Copyright: (C) the author(s), publisher and licensee Medip Academy. This is an open-access article distributed under the terms of the Creative Commons Attribution Non-Commercial License, which permits unrestricted non-commercial use, distribution, and reproduction in any medium, provided the original work is properly cited.

\begin{abstract}
Background: The study of the risk factors contributing to still birth is imperative in our attempts to bring about a decline in the still birth rate. By identifying the risk factors, we can understand the areas where specific interventions may be applied to bring about a reduction in the still birth rate. The aim of the present study was to identify the risk factors for stillbirth among the mothers attending Sri Avittom Thirunal Hospital, Trivandrum

Methods: This was a prospective hospital based case control study conducted from March 2014- September 2015. Sample size was calculated as 100 cases and 200 controls. Odds ratios with $95 \%$ confidence interval were calculated using multi variate logistic regression.

Results: The major risk factors associated with still births were maternal age, socio economic status, and obesity, sleep position during pregnancy, primi parity, hypertension and febrile illness during pregnancy. The risk of still birth was 3 times higher among mothers with hypertension compared to the control group. Although the prevalence of diabetes slightly more in the case group it was not statistically significant. By analyzing all the risk factors in preparing a model $42 \%$ of the risk for still birth was contributed by these factors.

Conclusions: The modifiable risk factors seen in this study to prevent still births are maternal sleep position during pregnancy, diabetes, hypertension and febrile illness especially urinary tract infection. By better antenatal care we can detect complications like diabetes, hypertension and manage appropriately thereby preventing complications. By screening for urinary tract infections in every trimester morbidity can be reduced.
\end{abstract}

Keywords: Hypertension, Maternal sleep position, Risk factors, Still birth

\section{INTRODUCTION}

Stillbirth is a major obstetric catastrophe at any gestational age but is not considered a resource priority in many countries. According to the WHO update, there were 2.6 million stillbirths in $2015 .^{1}$ This accounts for over 7178 deaths per day. It also states that among the stillbirths, the intrapartum loss ranges from $10 \%$ in developed nations to $59 \%$ in the developing nations. It has been noted that ninety eight percent of these deaths occur in the low and middle income nations. ${ }^{1}$ India has an estimated stillbirth rate of 22.1/1000 total births as noted in 2009. It is said that about $66 \%$ of the worldwide stillbirths is contributed by developing nations like India, Pakistan, Nigeria, China, Demographic Republic of Congo, Ethiopia, Bangladesh, Indonesia, Tanzania and Afghanistan. ${ }^{2}$ However, the Stillbirth rate has come down by $19.4 \%$ from 2000 to 2015 with various interventions. This indicates an annual decline of $2 \%$. $^{2}$ The definition of stillbirth varies in different settings with regards to the period of viability. This is largely because of the facilities available for neonatal care. A number of social and 
demographic factors are known to be associated with stillbirth, the degree of which varies from country to country. In order to bring about a decline in the stillbirth rate we should know the major contributing risk factors. This is imperative in taking steps to reduce the stillbirth rate. Stillbirth rate can be reduced by repeated periodic analysis of its negative and sensitive factors and by making necessary efforts to rectify them. The major causes of still birth are child birth complications, post term pregnancy, maternal infections, and maternal disorders like hypertension, diabetes, obesity, foetal growth restriction and congenital anomalies. ${ }^{3}$

Kerala is a state unique in the sense that it has made great strides in improving health care facilities. The Stillbirth rate of Kerala is $5.3 \%$ in $2010 .{ }^{4}$ In our hospital which is a tertiary care referral setup catering to the southern districts of Kerala and neighbouring state of Tamil Nadu we get mothers referred to us most often when the tragic event has already occurred. It has been an earnest effort on our side to identify the risk factors which might have attributed to the stillbirth. The aim of this study is to identify any possible modifiable risk factors and reduce stillbirth rate on a long-term perspective.

\section{METHODS}

It is a hospital based case control study aimed to identify the risk factors for stillbirth among the mothers attending Sri AvittomThirunal Hospital, Trivandrum.

Stillbirth is defined as the death of a foetus in utero before birth at or after 24 weeks of gestation or when the foetus is $500 \mathrm{gm}$ if the gestational age is not known. ${ }^{5}$ Cases taken were mothers with stillbirth admitted in SAT hospital. Two mothers with singleton births consecutive and next to the stillbirth in the labour room records were taken as controls. Sree Avittom Thirunal (SAT) Hospital is a tertiary care maternity hospital attached to the Government Medical College Trivandrum which provides service to referred cases from southern districts of Kerala and nearby districts of Tamil Nadu. Every year there are about 9400 deliveries and around 300 stillbirths reported. The study was conducted in this hospital from March 2014- September 2015.

Sample size was calculated with software Epi info for unmatched case control study with the following assumptions: two-sided confidence interval of 95\%., p value significance at $<0.05$, Power at $80 \%$, case to control ratio as $1: 2$, and prevalence of one major risk factor Gestational Diabetes mellitus in control as $10 \%$. The number of cases to be included is 100 and control 200 .

The study variables included were age, BMI, previous obstetric history, socioeconomic class, hypertension, diabetes mellitus, febrile illness, maternal sleep position during pregnancy, seizure disorder, thyroid disease, heart disease, bleeding in first trimester and IUGR.

\section{Methodology}

100 cases of stillbirth were included in the study and data was collected by personal interviews with structured questionnaire designed to meet the objective of the study. Data was also taken from the medical records and antenatal files.

\section{Statistical analysis}

The study variables were collected, and the data was entered in Excel format and verified. Statistical analysis was done using SPSS version 16. The bi-variate tables were constructed and Chi square test was done for statistical significance. Odds ratio was computed for each variable. Logistic regression analysis was done and Odds ratio with confidence interval was calculated for each variable.

\section{RESULTS}

The study done on 100 cases and 200 controls had mothers in the age group of 18 to 40 years. Most of the mothers were in the age group of 20-25 years followed by 25-30 years. About $83 \%$ patients were from rural area which is the general pattern seen in the hospital. Medical diseases like psychiatric illness, thyroid disease, seizure disorder, chronic hypertension, overt diabetes, heart disease in the mother, blood group, anemia, were found to be comparable in the study for cases and controls. $62 \%$ of the stillbirth were females. The mean birth weight in the case group was $1.478 \mathrm{~kg}$ and the control group was $2.723 \mathrm{~kg}$.

In univariate analysis, the major risk factors found to be associated with still birth were maternal age, socioeconomic status, and obesity, sleep position during pregnancy, parity, hypertension and febrile illness during pregnancy (Table 1). It was also noted that bleeding per vaginum in the first trimester was two times more in the stillbirth group. There was $47 \%$ occurrence of stillbirth among hypertensive mothers compared to controls. The risk of stillbirth was 3 times higher among mothers with hypertension compared to the control group. The prevalence of diabetes was slightly more in the case group. But the observed difference was not statistically significant. Adverse pregnancy outcome in the past showed an odd of 2.6 for stillbirth. Among the febrile illness UTI was a major contributor. There was $29 \%$ occurrence of UTI among stillbirth cases compared to controls. The risk of stillbirth was noted to be twice in mothers with UTI compared to the control group.

In logistic regression analysis, the risk factors found associated with still birth were maternal age, socioeconomic status, Obesity, sleep position during pregnancy, Parity, Hypertension and febrile illness during pregnancy (Table 2). By analysing all the risk factors in preparing a model, $42 \%$ of the risk for still birth is contributed by all these factors. 
Table 1: Risk factors for still birth.

\begin{tabular}{|c|c|c|c|c|c|}
\hline \multicolumn{2}{|l|}{ Risk Factor } & Cases $(\%)$ & Control (\%) & OR $(95 \% \mathrm{CI})$ & OR (95\% CI) \\
\hline \multirow{2}{*}{ Maternal Age } & $>30$ years & $24(24)$ & 3.399 & 3.399 & \multirow{2}{*}{$<0.001$} \\
\hline & $<30$ years & $76(76 \%)$ & $(1.728-6.686)$ & $(1.728-6.686)$ & \\
\hline \multirow{2}{*}{$\begin{array}{l}\text { Socioeconomic } \\
\text { Status }\end{array}$} & Lower Class & $22(22 \%)$ & & & \multirow{2}{*}{0.016} \\
\hline & Middle \& Upper Class & $78(78 \%)$ & 2.171 & 2.171 & \\
\hline \multirow{2}{*}{ BMI } & Overweight \&Obese & $45(45 \%)$ & $(1.142-4.216)$ & $(1.142-4.216)$ & \multirow{2}{*}{0.001} \\
\hline & Normal \&Underweight & $55(55 \%)$ & & & \\
\hline \multirow{2}{*}{$\begin{array}{l}\text { Sleep Position } \\
\text { During pregnancy }\end{array}$} & Not left lateral position & $43(43 \%)$ & 2.269 & 2.269 & \multirow{2}{*}{$<0.001$} \\
\hline & Left lateral position & $57(57 \%)$ & $(1.371-3.756)$ & $(1.371-3.756)$ & \\
\hline \multirow{2}{*}{ Parity } & Primi & $87(87 \%)$ & & & \multirow{2}{*}{0.002} \\
\hline & Multi & $13(13 \%)$ & 4.834 & 4.834 & \\
\hline \multirow{2}{*}{$\begin{array}{l}\text { Bleeding Per Vagina } \\
\text { in First trimester }\end{array}$} & Yes & $22(22 \%)$ & $(2.742-8.520)$ & $(2.742-8.520)$ & \multirow{2}{*}{$<0.001$} \\
\hline & No & $78(78 \%)$ & & & \\
\hline \multirow{2}{*}{$\begin{array}{l}\text { Gestational } \\
\text { Hypertension }\end{array}$} & Yes & $47(47 \%)$ & 2.733 & 2.733 & \multirow{2}{*}{$<0.001$} \\
\hline & No & $53(53 \%)$ & $(1.416-5.278)$ & $(1.416-5.278)$ & \\
\hline \multirow[t]{2}{*}{ Febrile Illness } & Yes & $18(18 \%)$ & & & \multirow{2}{*}{$<0.001$} \\
\hline & No & $82(82 \%)$ & 2.539 & 2.539 & \\
\hline \multirow{2}{*}{$\begin{array}{l}\text { Gestational } \\
\text { Diabetes }\end{array}$} & Yes & $27(27 \%)$ & $42(21 \%)$ & & \\
\hline & No & $73(73 \%)$ & $158(79 \%)$ & & \\
\hline
\end{tabular}

Table 2: Multivariable analysis by logistic regression of variables analysed for the risk of still birth.

\begin{tabular}{|l|l|l|l|l|l|l|l|l|}
\hline Variables & B & S.E & Wald & df & P value & OR & 95\% CI for OR \\
\hline Age (30 yrs) & 1.032 & 0.438 & 5.555 & 1 & 0.018 & 2.806 & 1.190 & 6.617 \\
\hline Income (<7000Rs) & 0.988 & 0.388 & 6.470 & 1 & 0.011 & 2.685 & 1.254 & 5.746 \\
\hline $\begin{array}{l}\text { Education (below } \\
\text { High school) }\end{array}$ & 0.719 & 0.315 & 5.206 & 1 & 0.023 & 2.052 & 1.107 & 3.806 \\
\hline Parity (Primi) & 1.322 & 0.431 & 9.398 & 1 & 0.002 & 3.750 & 1.611 & 8.730 \\
\hline BMI (Overweight) & 0.923 & 0.319 & 8.355 & 1 & 0.004 & 2.518 & 1.346 & 4.708 \\
\hline Sleep Pattern & 1.081 & 0.345 & 9.815 & 1 & 0.002 & 2.947 & 1.499 & 5.794 \\
\hline Bleeding PV & 1.322 & 0.533 & 6.155 & 1 & 0.013 & 3.749 & 1.320 & 10.651 \\
\hline Hypertension & 0.801 & 0.324 & 6.127 & 1 & 0.013 & 2.228 & 1.181 & 4.201 \\
\hline Febrile illness & 1.932 & 0.745 & 6.718 & 1 & 0.010 & 6.904 & 1.602 & 29.758 \\
\hline UTI & 0.394 & 0.383 & 1.062 & 1 & 0.303 & 1.484 & 0.701 & 3.141 \\
\hline
\end{tabular}

\section{DISCUSSION}

Maternal age was one of the major risk factor associated with still birth. In this study, $17 \%$ were in the high risk age group, which include $7 \%$ below 20 years, and $8 \%$ above 35 years. This was similar to other similar studies. ${ }^{5,6}$ Lucy D et al in his study found the highest no of foetal deaths occurred in the age of 35 years. Miller HS et al in their study investigated the incidence of pre-eclampsia, preterm labour, foetal disproportion, instrumental delivery and infection are high in teenage pregnancies. ${ }^{7}$ Whereas, in another study more than $35 \mathrm{yr}$ old mothers have the risk of developing preeclampsia, diabetes, macrosomia, stillbirth and postpartum complications. $^{8}$ Meis et al found that spontaneous preterm deliveries were associated with young maternal age whereas indicated preterm births were associated with older maternal age. ${ }^{9}$ All these influenced stillbirth rate separately. Annie Marie et al found that the highest number of foetal deaths occur in the age group of more than 30 years. In present study, maternal age more than 30 years was identified as a major factor determining the stillbirth.

Socio Economic status which is primarily a combination of education, occupation and income had an influence on the still birth rate. A study from Turkey identified that still birth and neonatal death was high in low socio economic status. ${ }^{10}$ Many Indian studies have corroborated the same findings. 5,6 The comprehensive rural health product says that demographic variables and socio economic variables are significant determinants of neonatal deaths. Since an educated mother assumes greater responsibility in planning her family and she also avails maternal services appropriately. It is a general observation that countries or regions with high female 
literacy ratio have low birth rates and mortality rates. According to NHFS the female literacy in Kerala is 93.91\%compared to whole state of India (74.04\%) and the still birth rate is $6 \%$ and $22 \%$ respectively. ${ }^{11,12}$

The risk of still births was two times more in the primigravida. A similar observation was noted by Hashim $\mathrm{N}$ in their study. ${ }^{12}$ This may be due high risk of preeclampsia and dystocia in primigravida leading to intrapartum still birth.

In this study, the risk of stillbirth was two times higher among overweight woman compared to controls. Similar observations were found by other studies as well. Overweight and obesity are leading factors for gestational hypertension and gestational diabetes which are leading factors of stillbirth. ${ }^{13}$

The risk of still birth was 4 times higher in mother's who did not sleep in their left lateral position. Similar observation was noted by another study. It is considered a potentially modifiable risk factor for late still birth especially in an already compromised foetus. ${ }^{14-16}$ Yet another study says that maternal body position in pregnancy has an influence on the maternal cardiac output and foetal oxygen saturation which may be the cause of increased foetal mortality. The risk of still birth was twice among those with bleeding per vaginum in the first trimester. Similar observations were seen in another study. ${ }^{17}$ About $0.4-1.3 \%$ of all pregnancies give history of first trimester vaginal bleeding which may occur due to uterine contractions and pain. ${ }^{18}$ A $22 \%$ occurrence of stillbirth was noted among the mothers with a history of bleeding per vaginum in the first trimester.

Previous adverse pregnancy outcome in the form of one still birth, 3 or more abortions, or one perinatal mortality was significantly associated with increase in still birth rate. These were in another study as well. In APLA syndrome thrombosis occurring in the implanting placenta result in fetal demise, fetal growth retardation and pre-eclampsia. The risk of still birth was more in gestational hypertension. There was $47 \%$ occurrence of still birth among hypertensive mothers. In a study from Orissa gestational hypertension accounted for $21.9 \%$ of still births. In yet another study of stillbirth it has been described that preeclampsia accounted for $18.9 \%$ of still births. Hypertension has a deleterious impact on the placenta which may lead to a poor fetal outcome. ${ }^{19}$ Severe pre-eclampsia increases the risk of abruption, small for gestational age and may lead to still birth.

There was an $18 \%$ occurrence of still births among mothers with history of febrile illness, like respiratory tract infection, urinary tract infection and other infections manifesting as fever. The risk of still birth was 10 times higher among mothers with febrile illness. Robert et al in their study say that $25 \%$ of the still births may be due to maternal infection. ${ }^{20}$ The different mechanisms that cause still birth may be by direct fetal infection, placental damage or chorioamnionitis. Infection occurring in early gestation may result in congenital anomalies and still birth later. Damage to the end organs, lung, heart, brain and fetal pneumonia can result in still birth. Intra uterine growth restriction increases the risk of stillbirth by 56 times. There was $22 \%$ occurrence of stillbirth in Intra uterine growth restriction babies compared to control. The mean birth weight in the case group was $1.478 \mathrm{~kg}$ and the control group was $2.723 \mathrm{~kg}$. This is supported by the Birmingham COGS project. Intra uterine growth restriction could be secondary to placental causes, chronic infection, congenital anomalies, poor nutrition, maternal anemia and maternal diseases like preeclampsia. Gestational diabetes was slightly more in the stillbirth group of our study but it was not found to be statistically significant. We consider this because of Berksonian bias.

The incidence of placenta previa, premature rupture of membranes, umbilical cord abnormalities, prolonged labour was comparable in both groups. The incidence of ante partum hemorrhage was significantly more in the case group. Still birth was 7 times more among fetus with cord around the neck. Meconium stained liquor showed 56 times more association with stillbirth. Meis et al prospectively evaluated 2923 pregnancies and documented a statistically significant increase in foetal heart rate abnormalities causing stillbirth and thick meconium. There was one case of stillbirth associated with rupture uterus. Of the stillborn babies $62 \%$ were females. When we looked at the risk factors associated with family history, the odds ratio for diabetes in family showed the risk of stillbirth was twice and it could reach a maximum value of 4.9 . The risk of stillbirth was 2.5 times more among those with family history of hypertension and in the community, it could reach a value of 5.1. The incidence of miscarriage, previous history of still birth, previous caesarean section was comparable in the both groups. Referred cases were significantly more in the case group. The risk of still birth was 17.7 times more in the referred cases and in the community. The risk could range from 9.7 to 32 . In both the groups there was early registration and immunization coverage. Intake of folic acids was found to be similar in both the groups.

\section{CONCLUSION}

The risk factors for still births identified in this study were maternal age, low socio economic status, obesity, maternal sleep position during pregnancy, primi parity, hypertension and febrile illness. Among the febrile illness urinary tract infection was the major contributor. Though diabetes is an important risk factor for stillbirth in our study we did not get a statistically significant association. This may be because of the Berksonian bias. It is recommended that planned pregnancies, proper antenatal care, high risk strategy classification, may contribute to reducing still births. Infections should be detected early and treated. Practitioners should be sensitized to screen all pregnant mothers for asymptomatic bacteriuria. 
Careful monitoring of the intra partum period should be emphasized in all labour rooms. Pregnant mothers should be advised to sleep in the left lateral position.

Funding: No funding sources

Conflict of interest: None declared

Ethical approval: The study was approved by the Institutional Ethics Committee

\section{REFERENCES}

1. World Health Organisation. Fact Sheet: Still Births, 2016. Available

at who.int/mediacentre/news/releases/2016/stillbirthsneonatal-deaths/en

2. Cousens S, Blencowe H, Stanton C, Chou D, Ahmed S, Steinhardt L et al. National, regional, and worldwide estimates of stillbirth rates in 2009 with trends since 1995: a systematic analysis. Lancet. 2011;377(9774):1319-30.

3. Flenady V, Koopmans L, Middleton P, Frøen JF, Smith $\mathrm{GC}$, Gibbons $\mathrm{K}$ et al. Major risk factors for stillbirth in high-income countries: a systematic review and metaanalysis. Lancet. 2011;377(9774):1331-40.

4. Annual Vital Statistics Report 2010, Department of Economics and Statistics, Govt. of Kerala. 2013.

5. Kannan MPB, Bhat V, Sharma R, Ferns S, Rani R. Perinatal mortality -Identification of Risk factors. J Obstet Gynaecol India. 2003:53(3):240-3.

6. Lucy D, Umakant S, Niharika P. Perinatal mortality in a referral hospital of Orissa-a 10-year review.

Obstet Gynaecol. 2005;55(6):57-5.

7. Miller HS, Najati N, Gojazadeh M. Maternal and neonatal complications in mothers aged under 18 years. Patient Prefer Adherence. 2010;4:219-22.

8. Renee A, Bobrowski MD, Sidney F, Bottoms MD. Under appreciated risk of elderly multipara American J Obstet gynaecol. 1995;172(6):1764-70.

9. Meis PJ, Michielutte R, Peters TJ, Wells B, Evan Sands $\mathrm{RE}$, Coles EC et al. Factors associated with preterm birth in Cardiff, Wales. Am $\mathrm{J}$ of Obstet gynaecol. 1995;173(2);590-6.

10. Erdem G. Perinatal mortality in Turkey. Paediatr Perinat Epidemiol. 2003;17(1):17-21.
11. NFHS Survey IIPS and DRC macro2001(b). http://rchiips.org/nfhs/nfhs3.shtml. National family Health survey-3 (2005-2006).

12. Hashmi N, Naqui S, Khanam M, Jafry HF. Primi parity as an intrapartum obstetric risk factor. J Pak Med Assoc. 2012:62;694-8.

13. Bodnar LM, Parks WT, Perkins K, Pugh SJ, Platt RW, Feghali $\mathrm{M}$ et al. Maternal pre-pregnancy obesity and cause specific stillbirth. Am J Clin Nutr. 2015;102(4):858-64.

14. Owusu JT, Anderson FJ, Coleman J, Oppong S, Seffah JD, Aikins A, et al. Association of maternal sleep practices with pre-eclampsia, low birth weight, and stillbirth among Ghanaian women. Int J Gynaeco Obstet. 2013;121(3):261-5.

15. Stacey T, Thompson JM, Mitchell EA, Ekeroma AJ, Zuccollo JM, McCowan LM. Association between maternal sleep practices and risk of late stillbirth: a case-control study. BMJ. 2011;14:342.

16. Gordon A, Raynes-Greenow C, Bond D, Morris J, Rawlinson W, Jeffery H. Sleep Position, Fetal Growth Restriction, and Late-Pregnancy Stillbirth: the Sydney stillbirth study. Obstet Gynecol. 2015;125(2):347-55.

17. Patel NG, Patel MS, Shah SR, Jani SK, Patel JA, Shah JU. Study of outcome of pregnancy in patients with first-trimester bleeding per vaginum. Int $\mathbf{J} \mathrm{Adv}$ Med. 2014;1(3):230-3.

18. Singh G, Sidhu MK. Bad Obstetric History: a prospective study. MJAFI. 2010;66(2):117-20.

19. Vigil-De Gracia P, Reyes Tejada O, Calle Miñaca A, Tellez G, Chon VY, Herrarte E, Villar A, Ludmir J. Expectant management of severe preeclampsia remote from term: the MEXPRE Latin Study, a randomized, multicenter clinical trial. Am J Obstet Gynecol. 2013;209(5):425.

20. Harrison MS, Robert L. Goldenberg. Global burden of prematurity. Seminars in fetal and neonatal medicine. 2016:21(2):74-9.

Cite this article as: Lakshmi ST, Thankam U, Jagadhamma P, Ushakumari A, Chellamma N, Hariharan SV. Risk factors for still birth: a hospital based case control study. Int J Reprod Contracept Obstet Gynecol 2017;6:970-4. 